\title{
Excessive Internet Use and Personality Traits
}

\author{
Georgios Floros • Konstantinos Siomos
}

Published online: 2 February 2014

(C) Springer International Publishing AG 2014

\begin{abstract}
Cases of excessive use of the Internet have been reported for some time, with numerous claimed adverse effects to the well-being of the subject. Objective signs and subjective symptoms are similar to those of addictive behavior, leading to the classification of those cases as incidences of an addiction disorder. Research results from this new field of study have led to the recent provisional introduction of a subset of those cases, those concerning online gaming, in the fifth edition of the Diagnostic \& Statistical Manual of Mental Disorders by the American Psychiatric Association (DSM-5) under the heading 'Internet Gaming Disorder'. This review article critically examines research conducted on the personality attributes of those Internet users who demonstrate signs and symptoms of excessive use. The results lend credit to the notion of including a disorder in psychiatric taxonomies yet do not cover all possible fields of research, rather focusing on trait personality psychology. Directions are offered for future research.
\end{abstract}

Keywords Excessive Internet use $\cdot$ Internet addiction · Personality $\cdot$ Personality and impulse control disorders . Internet Gaming Disorder · DSM-5 · Trait personality psychology

\section{Introduction}

In 2013 approximately $40 \%$ of the world's population was connected to the Internet via various devices [1]. The

G. Floros $(\bowtie)$

Second Department of Psychiatry, Aristotle University of

Thessaloniki, Thessaloniki, Greece

e-mail: georgefloros@gmail.com

G. Floros $\cdot$ K. Siomos

Hellenic Association for the Study of Internet Addiction Disorder, Larissa, Greece ubiquitous nature of the Internet in a modern society is attributed to its general usefulness and potential to simplify our daily lives while enhancing, or even enriching our experiences. Nevertheless, there have been reports of people who showed signs of using the Internet excessively to the detriment of their 'real' lives, time spent with their families and friends, and ability to meet their obligations [2,3]. A term being employed since the nineties to describe extreme cases of excessive Internet use (EIU) is the term 'Internet Addiction Disorder' (IAD). This term was coined as a practical joke, meant to reduce ad absurdum the practice of diagnosing pathological gambling with the symptom checklist employed in the manual of the American Psychiatric Association; the rationale being that if we could accept this practice as valid, then we could employ similar criteria to diagnose an addiction to everything. Unexpectedly however, some Internet users came forward, stating that they recognized themselves and their online habits in these mocked-up terms. This was a case of reality catching up with fiction, leading to a creation of a more general term, 'technological addictions', to describe problematic patterns of using technological means, including excessive use of personal computers (PC) and the Internet [4, 5]. It follows on the footsteps of the classical work by $\mathrm{Dr}$ Shirley Turkle, 'The Second Self', where the author described a subculture of computer programmers of the late seventies who were completely devoted to an artificial environment, their aim being no longer using but rather interacting with the PC [6].

Using terms related to the addiction paradigm to describe EIU was met with skepticism; the Internet was considered as simply providing a new pathway to express underlying psychopathology [7], while those few cases of overindulgence supposedly were a result of initial enthusiasm with the new medium and its enticing possibilities [8]. Research however, in large community samples that excluded those users diagnosed with any psychiatric disorders, showed that users with EIU had in fact more online experience, having been 
introduced earlier to the Internet than their peers $[9,10]$. The incidence of cases also increased rather than decreased, with numerous mental health services having been set up across the world. Our personal experience stems from setting up two of those services in Greece, on 2008 [11] and 2010 [12].

Since those early reports a multitude of published studies have marked the gradual increase of research interest in the subject; a NLM/PubMed query on the terms most frequently employed (addiction, dependence, abuse, compulsive, overindulgence, overuse, excessive/pathological/problematic use) has returned 498 results at the time of writing this report. This interest led to the consideration of including IAD in DSM-5 [13]. The wider debate referred to important classification questions: whether this concept merits inclusion as a primary disorder, whether IAD was a consequence of other underlying disorders, or whether individual activities like online gaming were the principal causes of harm [14]. Additionally, if IAD was to be considered a specific disease entity, should it be categorized in the Obsessive-compulsive Disorder (OCD) spectrum [15] or with other 'behavioral' addictions, like gambling? [16]. The authors of DSM-5 concluded, upon the inclusion of 'Internet Gaming Disorder' in "Conclusions", that it was a condition warranting more clinical research and experience, before it might be considered for inclusion as a formal disorder [17]. The fact that more research was available on the adverse outcomes of online gaming led to limitation of the scope to gaming rather than to general Internet use, online gambling or social networking. The proposed criteria are closely related to the original IAD criteria, which in turn originated from those criteria for pathological gambling several years ago.

Having accepted that there are at least some aspects of Internet use which lead to adverse outcomes for the excessive user, even if some common diagnostic criteria are eventually agreed upon, the question remains as to why one user would present with this behavior and another would not. Given that virtually every home in a 'First World' country is soon to have Internet access, this question assumes great value from a public health perspective; if we can identify those users vulnerable to excess then it is conceivable that we could prevent their excessive behavior. Not surprisingly then, a number of studies have tried to elucidate the factors associated with excessive use. Following the lead from addiction research, this included users' personality organization.

\section{Personality and Models of Addiction}

When we classify any behavior as excessive then a separate question arises as to whether the underlying personality organization contributes decisively to its origins. There is however a major methodological hurdle; the term 'personality' includes a great many theoretical models, quite often at odds with one another, representing partial views of an intrinsic totality [18].
Although psychiatry has approached the issue from the pathological point of view, defining a number of personality disorders, the large number of competing models seeking to describe 'normal' personality creates a difficulty in comparing research outcomes; typically, studies from different research teams employ research instruments and methodologies that differ from each other.

The field of personality theory that has been applied the most in EIU research is one comprised of various trait and factorial perspectives. Traits are single dimensions of individual differences, expressed consistently across time and pervasively across situations [18]. Various models have been proposed each with its own set of rules for grouping specific constellations of different responses to questions considered revealing of each trait. Some models were created after theorists such as Hans Eysenck [19] or Jeffrey Gray [20] posited the existence of specific traits and then proceeded to devise an appropriate research instrument (questionnaire) aided by factor-analytic statistical methodology. In those theories, an underlying neurobiological foundation is supposedly expressed through specific traits which persist in different situations across the lifespan, and are expressed more frequently in specific patient populations. The reverse approach, typified in the Five-Factor model (FFM) [21], was based upon the premise that, by factor-analyzing all the available personality characteristics in the relevant literature then we would reach a common set of basic traits that should have some neurobiological underpinning. Either way, results from the research conducted provide some basic understanding of how specific aspects of personality may be correlated and expressed in a similar manner in various contexts. The common characteristic of these models is the relative ease with which they can be applied to any research population with basic grammatical knowledge in a small amount of time, rendering the research effort easy to manage, easy to understand and low-cost. The models which have been employed in research of EIU in 34 identified studies include: Eysenck's PEN model (tested with the EPQ questionnaire) [19]; Gray's bio-psychological model (tested with the BIS \& BAS questionnaire) [20]; Cloninger's psychobiological model (tested with the TPQ questionnaire) [22]; Zuckerman's alternative FFM (tested with the SSS and ZKPQ questionnaires) [23]; the FFM (tested with the NEO-PI questionnaire) [21] and Cattell's 16 personality factors (tested with the 16PF) [24]. Those models propose various traits which share common names and features only in some cases. An effort was made for the benefit of the reader to group those traits by similarity, so as to make sense of their collected results. This grouping is presented in Table 1 . The more frequently employed scales for research were: the EPQ [25-32]; NEO-PI [33-47]; TPQ [48-51] and BIS \& BAS questionnaire [52-54]; with single studies carried out with the SSS [55] and 16PF [56]. We should note that, although the Lie factor was originally 
Table 1 Results from studies carried out on personality traits correlated with excessive Internet use

\begin{tabular}{|c|c|c|}
\hline Trait & Studies & Findings \\
\hline Psychoticism / negative valence & $\begin{array}{l}\text { Cao [25], Charlton \& Danford [34], Fisoun [27], } \\
\text { Yan et al [58], Xiuqin et al [32] }\end{array}$ & Positive correlation in all studies with EIU \\
\hline Extraversion & $\begin{array}{l}\text { van der Aa et al [33], Hardie \& Tee [28], Kuss } \\
\text { et al [35], Landers \& Lounsbury [37], Muller } \\
\text { et al [42], Peters \& Maletsky [43], Petrie \& } \\
\text { Gunn [44], Wilson et al [46], Yan et al [58], } \\
\text { Xiuqin et al [32] }\end{array}$ & Negative correlation in all studies with EIU \\
\hline $\begin{array}{l}\text { Neuroticism / BIS reactivity / emotional } \\
\text { stability/ sensitivity to punishment }\end{array}$ & $\begin{array}{l}\text { van der Aa et al [33], Cao et al [25], Charlton \& } \\
\text { Danford [34], Dong et al [26], Fisoun [27], } \\
\text { Hardie \& Tee [28], Kuss et al [36], Meerkerk } \\
\text { at al, [54], Mehroof \& Griffiths [29], Muller } \\
\text { et al [42], Peters \& Maletsky [43], Tsai et al. } \\
\text { [31], Yan et al [58], Yang et al [56], Young } \\
\text { \& Rodgers [47] }\end{array}$ & Positive correlation in all studies with EIU \\
\hline Conscientiousness / EPQ Lie & $\begin{array}{l}\text { Cao et al [25], Fisoun [27], Kuss et al [35], } \\
\text { Montag et al [41], Muller et al [42], Peters } \\
\text { \& Maletsky [43], Rahmani \& Lavasani [45], } \\
\text { Wilson et al [46], Young \& Rodgers [47] }\end{array}$ & $\begin{array}{l}\text { Negative correlation with EIU, especially in } \\
\text { non-productive contexts (like excessive } \\
\text { online gaming and social networking) }\end{array}$ \\
\hline $\begin{array}{l}\text { Sensation/ excitement/ novelty/ fun seeking, } \\
\text { openness }\end{array}$ & $\begin{array}{l}\text { Claes et al [52, 53], Dalbudak et al [59], Ko et al } \\
\text { [48-50], Lin \& Tsai [55], Lavin et al [38], } \\
\text { McElroy \& Hendrickson [39], Shi et al [60], }\end{array}$ & $\begin{array}{l}\text { Positive correlation with EIU except for the } \\
\text { Lavin study which reported negative } \\
\text { correlation }\end{array}$ \\
\hline Reward dependence (RD) / sensitivity (RS) & Ko et al [48-50] & Negative correlation in all studies with EIU \\
\hline Agreeableness / sentimentality & $\begin{array}{l}\text { Charlton \& Danford [34], Ko et al [49], Kuss et al } \\
\text { [36], Peters \& Maletsky [43], Rahmani \& } \\
\text { Lavasani [45] }\end{array}$ & Negative correlation in all studies with EIU \\
\hline Self-directedness / persistence / perseverance & $\begin{array}{l}\text { Ko et al [49], Montag et al [40, 41], Mottram \& } \\
\text { Fleming [30] }\end{array}$ & Negative correlation in all studies with EIU \\
\hline
\end{tabular}

included in the EPQ to provide a reliability scale, there were reports that it merits a separate analysis as an index of social conformity [57], and it appears to correlate with the typically high degree of social immaturity of drug addicts. For this reason it is grouped together with Conscientiousness in Table 1 and this grouping could be appropriate for other reliability scales as well in trait research.

The grouped results show us an obvious pattern, with those individuals scoring higher in measures of EIU also scoring higher scores in the basic traits of Psychoticism, Neuroticism, Sensation / Excitement seeking and lower scores in Extraversion, Reward Dependence (RD), Conscientiousness, Agreeableness and Self-Directedness (SD).

From a psychological point of view, the predominance of those traits in excessive users infer certain characteristics; those individuals who score higher than average in Psychoticism are thought to be more aggressive, assertive, manipulative, dogmatic and tough-minded, while being more likely to display extreme manifestations of psychic anguish, including feats of rage and psychotic breakdowns from reality. Higher scores in Neuroticism are linked to individuals with difficulty to self-regulate, leading to inner tension, anxiety, feelings of guilt, low self-esteem and mood swings. Sensation seeking is conceptualized as a construct related to Psychoticism but different to the extent that the individual is fixated in seeking out sources of pure excitement, rather than long-lasting achievements. Low scores in Extraversion are expected in persons who are not keen to take center stage or readily express themselves, are unlikely to seek instant sources of gratification, take risks or make rash decisions, but rather tend to ruminate in thought, be passive and seek solitude. Low scores in RD are found in conservative persons with low impulsiveness and drive, who are less likely to respond to social cues and gratifications. Conscientiousness and Agreeableness are also closely linked to (low scores of) Psychoticism, from which they differ in that their motivation for the goal-oriented behavior is respectively either rooted in dedication to a higher value, or to the well-being of those persons close to them. Thus, in persons with low scores in those two variables, as is the case in the EIU samples, there is a distinct lack of consideration for societal norms and expectations as a motivating factor. Interestingly, studies employing the EPQ that involved chemical-dependents and drug addicts have consistently demonstrated a similar pattern of scoring higher on the Psychoticism and Neuroticism factors, and lower on the Lie factor; those were dubbed "high addiction scores", ( $\mathrm{P}+, \mathrm{N}+$ and $\mathrm{L}-)$ [61, 62]. Neuroticism has been reported as possibly being artificially inflated during the course of drug addiction and contact with corresponding services, rather than being a primary finding [61]. The consensus on high Neuroticism in the presented studies is relatively unique to EIU and it was found on population samples 
as well, rather than those subjects in touch with health services. One possible explanation would be that high scores on Neuroticism are an artifact of frequent comorbidity of EIU with other mental disorders, in which case the subject turns to the Internet to alleviate psychic pain; this hypothesis can only be confirmed however with a large clinical sample.

To summarize, results from trait personality studies of EIU indicate that persons with excessive Internet use are typically self-centered and distant; face difficulties in regulating their feelings and are prone to fits of anger; are only motivated by short-term gratification of their needs; face challenges in relating to others; feel superior and display bravado, while at the same time being unsure of themselves and shying away from direct challenges.

Some of the aforementioned trait theories $[19,20]$ claim that the underpinnings for these traits are essentially neurobiological. If we accept this premise, then an addicted person could have a specific neurobiological 'profile' as well, one possibly linked to predilection for addictive behaviors. Research on neurobiological correlates of addiction has attempted for some time to determine alterations in brain chemistry and functionality linked to the expression of addictive behavior. Dysfunction of dopamine neurotransmission in particular has been highlighted as a finding for some time. Activation of this pathway is critical for the acute rewarding effects of psycho-stimulants and also has an enabling function for all other drugs [63]. Multiple findings verify a hypothesis that such a dysfunction in the mesocorticolimbic reward pathway is found both in drug addiction [64] and excessive gambling, the 'prototypical' behavioral addiction $[65,66]$. Dopamine receptors $D_{2}, D_{3}$ and $D_{4}$ are demonstrating a high level of polymorphism in addictive behaviors, although multiple other receptors have also been implicated in a smaller number of studies, as has the relative differences in $\mathrm{D}_{2} / \mathrm{D}_{3}$ ratio levels [67-69]. The proposed dopamine hypothesis for addiction that attempts to explain these experimental results maintains that, since excessive dopamine functioning that is directly induced by an addictive behavior increases its incidence, individuals in whom inherent dopamine functioning is below par would be readily addicted to those types of behavior which are reinforcing, and will continue to indulge in these behaviors, even after the circumstances giving rise to them have changed. The reverse hypothesis states that high levels of dopamine receptors may protect against addictions, as shown in a related study where higher than normal $\mathrm{D}_{2}$ receptor availability was found in nonalcoholic members of alcoholic families [70]. Those personality traits found to associate with individual variability in dopamine functioning include high Psychoticism [71, 72] and high Novelty Seeking [73], while there are conflicting findings for the Extraversion trait. A recent meta-analysis has suggested caution in similar claims, since this picture may be obscured due to interaction effects between genes and the environment [74], as witnessed in a related study [75]. Additionally, since all addictive substances tap into the neural reward mechanisms [76], the hypothesis that an increase in the trait RD would be correlated with dopamine receptor polymorphism was confirmed relatively early on [77].

Following the lead of chemical addiction research, similar studies were set up to investigate possible direct evidence of the similarities in the neurobiological profiles between EIU and other addictions. A review of the literature of neurobiological research on EIU [78] found nearly all comparative studies reporting similarities between affected Internet users and those suffering from substance dependence and impulse control disorders, with regard to poor behavioral inhibition and high impulsivity. EIU, especially in cases related to excessive online game playing, was directly associated with dopaminergic system dysregulation $[79,80,81 \bullet$, 82•]. Interestingly, genetic polymorphisms of the dopaminergic system correlated with higher levels of RD and RS [51, 83, 84••], rather than the lower levels claimed in the aforementioned non-experimental studies. In this respect the results from the three studies by Ko et al mentioned earlier [48-50] are surprising. The authors explained their results by speculating that low RD is associated with impairments in social reinforcement of acceptable behavior, along with poor persistence in task-oriented action, thus fitting the profile of an Internet addict that seeks immediate and predictable sources of gratification, rather than face possible frustrations with real-life tasks. In light however of the 'hard' evidence provided by neuroimaging and gene analysis, it is more appropriate to conclude that RD is typically increased in EIU; cultural factors of that particular environment (South Korea) or differences in the definition of EIU may be factoring in those results. In our clinical experience with affected college students during the last three years [12], there have been several individuals who would fit the above character description; clinical subtyping would help discern the profiles of affected users, work which is currently in progress with our research team.

A related recent important finding from Dong et al [84••] was that when faced with a gambling task, subjects with IAD had similar responses to those from addicted gamblers; enhanced sensitivity to win and decreased sensitivity to lose. According to the authors this would provide an explanation as to why subjects continue despite the adverse effects to their well-being. We would add that this study provides some evidence for including IAD along with pathological gambling in the field of behavioral addiction.

\section{Methodological Issues with Personality Trait Studies}

Research quoted so far has had a number of additional shortcomings, other than the lack of common language between different personality models, working definitions of EIU in general, and IAD in particular. The principal one is poor 
generalization of the results. Most studies were conducted either on small, convenience samples which do not represent any particular population; on samples of specific ages (e.g. high school or college students); or on highly specific samples with other co-existing psychopathology or limited scope of online interests (game players, social networkers). Replications of the obtained results is rendered near-impossible since one should consider that the demographics of online users were constantly shifting during the time frame 1990-2010, as were their online preferences and even the nature of those online preferences (e.g. types of favorite online games). Also, cultural factors may play an important role, with certain Internet 'fads' more prominent in specific countries or entire regions. Still, the surprisingly consistent findings throughout the vast majority of those studies are of certain value. Focusing on specific populations with consistent online habits (e.g. an online community with a long-standing interest in specific types of online games) may in fact be the sole possibility to enable future comparisons between studies. Settling upon a common definition for IAD would promote research, and the new criterion based definition for online game disorder in DSM-5 is expected to do just that, to the possible detriment of research in other fields of EIU.

\section{Alternate Directions in Personality Research on Excessive Use of the Internet}

\section{Excessive Internet Use and Personality Disorders; an Under-Researched Field}

Research presented so far stems from the viewpoint that some personality traits are more prominent in those demonstrating addictive behaviors, in our case with the Internet. The reverse notion is that certain addictive behaviors are so common among specific personality disorders (borderline, antisocial) as to be considered amongst the defining criteria for their diagnosis [17]. This possible reverse link is under-researched in EIU; a single study reported some comorbidity with clinically diagnosed obsessive-compulsive, borderline and avoidant personality disorders, in a small clinical sample, treated for other psychiatric diseases [15]. There is also a paucity of studies employing standardized measures of personality disorders in either clinical or the general population; there are no studies employing structured clinical interviews for personality disorders and only two studies employing the MMPI scale [85], the prototypical scale assessing personality issues related to psychopathology. Those two studies reported that three MMPI-2 subscales measuring personality patterns usually associated with substance addiction (MAC-R, APS, AAS), differentiate problematic video gaming from enthusiastic gaming [86], while measures of EIU correlated with the MMPI-2 Addiction Potential Scale [87]. Certain constructs related to personality pathology, like narcissism, have been mentioned in related research; narcissistic personality traits were positively correlated with online game addiction in a single study [88]. There's a lot of media attention on the possibility that narcissism may be a factor contributing to involvement with social networking sites (SNS), yet a recent study concluded that, while narcissists have different reasons than non-narcissists to use SNS, they do not appear to use them more often [89]. Clearly there's room for more research in the field of personality pathology and EIU, although the results may be counter-intuitive.

\section{Online Manifestations of Hidden Personality Traits}

A unique issue with personality research online is both intriguing and puzzling. Every online communicator that withholds some parts of his identifying information is said to possess an 'avatar', a term that has been loosely described as the online persona that the user is assuming, and is specific to that particular online environment. There has been considerable research interest in the meaning that the avatar assumes for the user, something clearly outlined by the considerable personal psychological investment in it [90]. The avatar is claimed to provide a unique online outlet for the user's 'true self' [91]. The 'true' or 'real' self is a concept put forward in various forms by Jung, Rogers and Winnicott, stating that an alternate personality construct exists at the same time with the manifest personality ('persona' or 'actual self' or 'false self' respectively), yet represents a fuller personality that the subject ideally should strive for. Two interesting parallels are worth noting here; that of the origins of the words 'personality' and 'avatar'. The etymology of the word personality stems from the Latin persona originally representing the theatrical mask used by ancient dramatic players which had to express the feelings associated with their part in the drama, not by the expressions of their face, but solely with the use of this indirect means. 'Avatar' on the other hand in Hinduism represents the descent of a deity to earth in an immaterial, phantom-like form. Basic etymology it seems, corresponds to an understanding of an avatar as being something valuable, but only manifest in an imaginary world, while personality in an offline context is but a mere mask that the user discards when he joins the online world. Regardless of whether one ascribes to the concept of an alternate, hidden self, the parallels here create a novel problem for research; if the behavior ascribed to an online user is atypical for him in an offline context, then can we truly generalize from his online behavior as to his motivations and intrinsic qualities, or are we studying unique aspects of his behavior that will not be repeated offline? Is the online behavior a proxy of a deeper psychological constellation or a true mirror of the user's personality as expressed with his daily interactions in the 'real' world? Those questions are still open to research. A study attempting to relate the concept of 'real' self with trait psychology reported those subjects low on 
Extraversion and high on Neuroticism located their 'real me' on the Internet, rather than through traditional social interaction [92]; this trait profile resembles the profile of excessive users mentioned above. If these results are replicated with excessive users then it could mean that the need to express one's 'true' self online could be a predisposing factor for EIU. Caution is required however when creating theory from correlations; the placement of this new 'true' self concept in personality research is far from decided, and ad-hoc terminology could be deceiving; if a user assumes a threatening or manipulative persona while online, would that not constitute character pathology?

\section{Conclusions}

Research on the link between personality attributes and various aspects of excessive Internet use has so far resulted in surprisingly consistent results, considering the complexity of researching a phenomenon without a concise definition that includes multiple and diverse behaviors. Various trait personality theories have featured prominently in research design so far, while several neurobiological studies have been conducted recently, increasing the validity of the notion to include online addictive phenomena in the psychiatric taxonomies. Results from all of those studies show remarkable similarities with other addictive behavior; more research however is needed, with measures from the field of abnormal psychology and personality disorders in particular. Research design should make an attempt to employ samples more representative of the general online user population or focus on specific activities, employing clinical samples whenever possible, rather than accepting results from a single questionnaire as denoting 'addiction'.

\section{Compliance with Ethics Guidelines}

Conflict of Interest Georgios Floros and Konstantinos Siomos serve as board members of the non-profit Scientific Association "Hellenic Association for the Study of Internet Addiction Disorder" into 2014.

Human and Animal Rights and Informed Consent This article does not contain any studies with human or animal subjects performed by any of the authors.

\section{References}

Papers of particular interest, published recently, have been highlighted as:

- Of importance

•• Of major importance

1. I.T.U Telecommunication Development Sector, World Telecommunication/ ICT Indicators Database Online. 2013, I.T.U.
2. Young KS. Internet addiction: the emergence of a new clinical disorder. Cyberpsych Behav. 1996;1:237-44.

3. Young KS. Psychology of computer use: XL. Addictive use of the Internet: a case that breaks the stereotype. Psychol Rep. 1996;79: 899-902.

4. Goldberg M. Technological addictions. Clin Psychol Forum. 1998:76:14-9.

5. Griffiths MD. Internet addiction: an issue for clinical psychology. Clin Psychol Forum. 1996;97:32-6.

6. Turkle S. The second self: Computers and the human spirit. New York: Simon \& Schuster, Inc.; 1984.

7. Stern SE. Addiction to technologies: a social psychological perspective of Internet addiction. Cyberpsychol Behav. 1999;2:419 24.

8. Grohol JM. Too much time online: internet addiction or healthy social interactions? Cyberpsychol Behav. 1999;2:395-401.

9. Siomos $\mathrm{K}$ et al. Evolution of Internet addiction in Greek adolescent students over a two-year period: the impact of parental bonding. Eur Child Adolesc Psychiatry. 2012;21:211-9.

10. Durkee $\mathrm{T}$ et al. Prevalence of pathological internet use among adolescents in Europe: demographic and social factors. Addiction. 2012;107:2210-22.

11. Siomos K et al. Presentation of a specialized outpatient unit for internet and PC addiction-first year of operations, results, recommendations for the future. Eur Psychol. 2010;25:413.

12. Floros G, Garyfallos G, Giouzepas J. Student counseling service for problematic use of the Internet and personal computers. Presentation of the first two years of operation. In WPA Thematic Conference - 4th INA European Congress - 1st Congress on Psychiatry and Related Sciences. 2012: Athens.

13. O'Brien C. Addiction and dependence in DSM-5. Addiction. 2011;106:866-7.

14. Pies R. Should DSM-5 designate "Internet addiction" a mental disorder? Psychiatry. 2009;6:31.

15. Bernardi S, Pallanti S. Internet addiction: a descriptive clinical study focusing on comorbidities and dissociative symptoms. Compr Psychiatry. 2009;50:510-6.

16. Grant JE et al. Introduction to behavioral addictions. Am J Drug Alcohol Abuse. 2010;36:233-41.

17. APA. Diagnostic and statistical manual of mental disorders. 5th ed. (DSM-5). American Psychiatric Publishing, Inc.; 2013.

18. Millon $\mathrm{T}$ et al. Personality disorders in modern life. 2nd ed. NJ: Wiley; 2004.

19. Eysenck HJ, Eysenck MW. Personality and individual differences: A natural science approach. New York: Plenum Press; 1985.

20. Gray JA. A critique of Eysenck's theory of personality, in A model for personality. New York: Springer; 1981. p. 246-76.

21. McCrae RR, John OP. An introduction to the five-factor model and its applications. J Pers. 1992;60:175-215.

22. Cloninger CR, Svrakic DM, Przybeck TR. A psychobiological model of temperament and character. Arch Gen Psychiatry. 1993;50:975.

23. Zuckerman $\mathrm{M}$ et al. A comparison of three structural models for personality: the Big Three, the Big Five, and the Alternative Five. J Pers Soc Psychol. 1993;65:757-7.

24. Cattell RB, Kline PE. The scientific analysis of personality and motivation. New York: Academic Press; 1977.

25. Cao F, Su L. Internet addiction among Chinese adolescents: prevalence and psychological features. Child Care Health Dev. 2007;33: 275-81.

26. Dong $\mathrm{G}$ et al. Risk personality traits of Internet addiction: A longitudinal study of Internet-addicted Chinese university students. Psychiatry: Asia-Pacific; 2012.

27. Fisoun $\mathrm{V}$ et al. Internet addiction as an important predictor in early detection of adolescent drug use experience-implications for research and practice. J Addict Med. 2012;6:77-84. 
28. Hardie E, Tee MY. Excessive internet use: the role of personality, loneliness and social support networks in internet addiction. Aust $\mathrm{J}$ Emerg Technol Soc. 2007;5:34-47.

29. Mehroof M, Griffiths MD. Online gaming addiction: the role of sensation seeking, self-control, neuroticism, aggression, state anxiety, and trait anxiety. Cyberpsychol Behav Soc Netw. 2010;13: 313-6.

30. Mottram AJ, Fleming MJ. Extraversion, impulsivity, and online group membership as predictors of problematic Internet use. Cyberpsychol Behav. 2009;12:319-21.

31. Tsai HF et al. The risk factors of Internet addiction - a survey of university freshmen. Psychiatry Res. 2009;167:294-9.

32. Xiuqin $\mathrm{H}$ et al. Mental health, personality, and parental rearing styles of adolescents with Internet addiction disorder. Cyberpsychol Behav Soc Netw. 2010;13:401-6.

33. van der Aa $\mathrm{N}$ et al. Daily and compulsive internet use and wellbeing in adolescence: a diathesis-stress model based on big five personality traits. J Youth Adolesc. 2009;38:765-76.

34. Charlton JP, Danforth IDW. Validating the distinction between computer addiction and engagement: online game playing and personality. Behav Inform Tech. 2010;29:601-13.

35. Kuss DJ et al. Internet addiction in adolescents: prevalence and risk factors. Comput Hum Behav. 2013;29:1987-96.

36. Kuss DJ, Griffiths MD, Binder JF. Internet addiction in students: prevalence and risk factors. Comput Hum Behav. 2013;29:959-66.

37. Landers RN, Lounsbury JW. An investigation of Big Five and narrow personality traits in relation to Internet usage. Comput Hum Behav. 2006;22:283-93.

38. Lavin $\mathrm{M}$ et al. Sensation seeking and collegiate vulnerability to Internet dependence. Cyberpsychol Behav. 1999;2:425-30.

39. McElroy JC et al. Dispositional factors in internet use: personality versus cognitive style. MIS Q. 2007;31:809-20.

40. Montag C, Jurkiewicz M, Reuter M. Low self-directedness is a better predictor for problematic internet use than high neuroticism. Comput Hum Behav. 2010;26:1531-5.

41. Montag $\mathrm{C}$ et al. Internet addiction and personality in first-personshooter video gamers. J Media Psych Theories Met Appl. 2011;23: 163.

42. Müller $\mathrm{K}$ et al. Addressing the question of disorder-specific risk factors of internet addiction: a comparison of personality traits in patients with addictive behaviors and co-morbid internet addiction. BioMed Res Int. 2013. doi:10.1155/2013/546342.

43. Peters CS, Malesky Jr LA. Problematic usage among highlyengaged players of massively multiplayer online role playing games. Cyberpsychol Behav. 2008;11:481-4.

44. Petrie H, Gunn D. Internet "addiction": The effects of sex, age, depression, and introversion. In: Paper presented at the British Psychological Society Conference. London; 1998.

45. Rahmani S, Lavasani MG. The relationship between internet dependency with sensation seeking and personality. Procedia Soc Behav Sci. 2011;30:272-7.

46. Wilson K, Fornasier S, White KM. Psychological predictors of young adults' use of social networking sites. Cyberpsychol Behav Soc Netw. 2010;13:173-7.

47. Young KS, Rodgers RC. Internet addiction: Personality traits associated with its development. In: 69th annual meeting of the Eastern Psychological Association. 1998.

48. Ko C et al. Tridimensional personality of adolescents with internet addiction and substance use experience. Can J Psychiatr. 2006;51: 887.

49. $\mathrm{Ko} \mathrm{CH}$ et al. Factors predictive for incidence and remission of internet addiction in young adolescents: a prospective study. Cyberpsychol Behav. 2007; 10:545-51.

50. Ko C-H et al. The characteristics of decision making, potential to take risks, and personality of college students with Internet addiction. Psychiatry Res. 2010;175:121-5.
51. Han DH et al. Dopamine genes and reward dependence in adolescents with excessive internet video game play. J Addict Med. 2007;1:133-8.

52. Claes $\mathrm{L}$ et al. The relationship between compulsive buying, eating disorder symptoms, and temperament in a sample of female students. Compr Psychiatry. 2011;52:50-5.

53. Claes $\mathrm{L}$ et al. The relationship among compulsive buying, compulsive internet use and temperament in a sample of female patients with eating disorders. Eur Eat Disord Rev. 2012;20:126-31.

54. Meerkerk G-J et al. Is compulsive internet use related to sensitivity to reward and punishment, and impulsivity? Comput Hum Behav. 2010;26:729-35.

55. Lin S, Tsai C. Sensation seeking and internet dependence of Taiwanese high school adolescents. Comput Hum Behav. 2002;18:411-26.

56. Yang C et al. SCL-90-R and 16PF profiles of senior high school students with excessive internet use. Can J Psychiatry. 2005;50:407.

57. Pearson PR, Francis LJ. The dual nature of the Eysenckian lie scales: are religious adolescents more truthful? Personal Individ Differ. 1989;10:1041-8.

58. Yan W, Li Y, Sui N. The relationship between recent stressful life events, personality traits, perceived family functioning and internet addiction among college students. Stress Health. 2013. doi:10. 1002/smi.2490.

59. Dalbudak E et al. Relationship of internet addiction severity with depression, anxiety, and alexithymia, temperament and character in university students. Cyberpsychol Behav Soc Netw. 2013;16:272-8.

60. Shi J, Chen Z, Tian M. Internet self-efficacy, the need for cognition, and sensation seeking as predictors of problematic use of the Internet. Cyberpsychol Behav Soc Netw. 2011;14:231-4.

61. Gossop M, Eysenck S. A further investigation into the personality of drug addicts in treatment. Br J Addict. 1980;75:305-11.

62. Kirkcaldy B et al. Predictors of drug and alcohol abuse among children and adolescents. Personal Individ Differ. 2004;36: $247-65$.

63. Koob GF, Volkow ND. Neurocircuitry of addiction. NeuroPsychopharmacology. 2009;35:217-38.

64. Bressan R, Crippa J. The role of dopamine in reward and pleasure behaviour-review of data from preclinical research. Acta Psychiatr Scand. 2005;111:14-21.

65. Steeves T et al. Increased striatal dopamine release in Parkinsonian patients with pathological gambling: a [11C] raclopride PET study. Brain. 2009;132:1376-85.

66. Zack M, Poulos CX. A D2 antagonist enhances the rewarding and priming effects of a gambling episode in pathological gamblers. Neuro-Psychopharmacology. 2007;32:1678-86.

67. Kreek MJ et al. Genetic influences on impulsivity, risk taking, stress responsivity and vulnerability to drug abuse and addiction. Nat Neurosci. 2005;8:1450-7.

68. Boileau I et al. The D2/3 dopamine receptor in pathological gambling: a positron emission tomography study with [11C]-(+)-propyl-hexahydro-naphtho-oxazin and [11C] raclopride. Addiction. 2013;108:953-63.

69. Clark L et al. Striatal dopamine D2/D3 receptor binding in pathological gambling is correlated with mood-related impulsivity. NeuroImage. 2012;63:40-6.

70. Volkow ND et al. High levels of dopamine $\mathrm{D}_{2}$ receptors in unaffected members of alcoholic families: possible protective factors. Arch Gen Psychiatry. 2006;63:999.

71. Gray N, Pickering A, Gray J. Psychoticism and dopamine D2 binding in the basal ganglia using single photon emission tomography. Personal Individ Differ. 1994;17:431-4.

72. Colzato L et al. Closing one's eyes to reality: evidence for a dopaminergic basis of psychoticism from spontaneous eye blink rates. Personal Individ Differ. 2009;46:377-80. 
73. Benjamin $\mathrm{J}$ et al. Population and familial association between the D4 dopamine receptor gene and measures of novelty seeking. Nat Genet. 1996;12:81-4.

74. Munafò MR et al. Association of the dopamine D4 receptor (DRD4) gene and approach-related personality traits: metaanalysis and new data. Biol Psychiatry. 2008;63:197-206.

75. Ozkaragoz T, Noble EP. Extraversion: interaction between D2 dopamine receptor polymorphisms and parental alcoholism. Alcohol. 2000;22:139-46.

76. Hyman SE, Malenka RC, Nestler EJ. Neural mechanisms of addiction: the role of reward-related learning and memory. Annu Rev Neurosci. 2006;29:565-98.

77. Ebstein RP et al. 5-HT2C (HTR2C) serotonin receptor gene polymorphism associated with the human personality trait of reward dependence: Interaction with dopamine D4 receptor (D4DR) and dopamine D3 receptor (D3DR) polymorphisms. Am J Med Genet. 1997;74:65-72.

78. Kuss DJ, Griffiths MD. Internet and gaming addiction: a systematic literature review of neuroimaging studies. Brain Sci. 2012;2:34774.

79. Koepp $\mathrm{M}$ et al. Evidence for striatal dopamine release during a video game. Nature. 1998;393:266-7.

80. Weinstein AM. Computer and video game addiction-a comparison between game users and non-game users. Am J Drug Alcohol Abuse. 2010;36:268-76.

81. Hou, H, et al. Reduced striatal dopamine transporters in people with internet addiction disorder. BioMed Res Int. 2012;2012. A study that demonstrates reduced dopamine availability in IAD due to reduced transport to target cells.

82. Kim SH et al. Reduced striatal dopamine D2 receptors in people with Internet addiction. NeuroReport. 2011;22:407-11. A study demonstrating reduced numbers of D2 receptors in IAD, similar to other addictive diseases.
83. Dong G, Huang J, Du X. Enhanced reward sensitivity and decreased loss sensitivity in Internet addicts: an fMRI study during a guessing task. J Psychiatr Res. 2011;45:1525-9.

84.• Dong G, Hu Y, Lin X. Reward/punishment sensitivities among internet addicts: implications for their addictive behaviors. Prog Neuro-Psychopharmacol Biol Psychiatry. 2013;46:139-45. This study demonstrated that IAD subjects showed enhanced sensitivity to win and decreased sensitivity to lose on a gambling task; those results are similar to those of addicted gamblers, providing a rationale for contiuous use despite negative consequences and conceptual similarities to behavioral addictions rather than OCD-spectrum disorders.

85. Butcher JN et al. MMPI-2: Minnesota multiphasic personality inventory-2. Minneapolis: University of Minnesota Press; 2003.

86. Spekman ML et al. Gaming addiction, definition and measurement: a large-scale empirical study. Comput Hum Behav. 2013;29:2150-5.

87. Armstrong L, Phillips JG, Saling LL. Potential determinants of heavier internet usage. Int J Hum Comput Stud. 2000;53:537-50.

88. Kim EJ et al. The relationship between online game addiction and aggression, self-control and narcissistic personality traits. Eur Psychiatry. 2008;23:212-8.

89. Bergman SM et al. Millennials, narcissism, and social networking: what narcissists do on social networking sites and why. Personal Individ Differ. 2011;50:706-11.

90. Yee N. The demographics, motivations, and derived experiences of users of massively multi-user online graphical environments. Presence Teleoperators Virtual Environ. 2006;15:309-29.

91. Bargh JA, McKenna KY, Fitzsimons GM. Can you see the real me? Activation and expression of the "true self" on the Internet. J Soc Issues. 2002;58:33-48.

92. Amichai-Hamburger Y, Wainapel G, Fox S. "On the internet no one knows i'm an introvert": extroversion, neuroticism, and internet interaction. Cyberpsychol Behav. 2002;5:125-8. 